\title{
ОБОБЩЕННЫЕ ПРИЕМЫ ДЕЯТЕЛЬНОСТИ ПО ВЫПОЛНЕНИЮ ЗАДАНИЙ МЕТОДОЛОГИЧЕСКОГО БЛОКА ЕГЭ
}

\section{GENERALIZED METHODS OF SOLVING THE METHODOLOGICAL BLOCK ASSIGNMENTS OF THE UNIFIED STATE EXAM}

\section{R. Petrova \\ F. Sidorova}

Summary: The Federal Educational Standards of the second generation requires the formation of students' skills, which are tested through the model tasks of the control and measuring materials of the Unified State Examination in Physics. Test tasks check whether the student owns the techniques of research activity using the empirical method of cognition. The classification of the methodological block assignments of the Unified State Examination has been carried out, therefore six types of tasks have been identified. Generalized methods for the implementation of assignments of six types have been developed, based on the structure of activities described in the planned results. The application of generalized techniques to specific assignments of the methodological block of the Unified State Exam proved the effectiveness of their use.

Keywords: methodological skills, generalized methods of activity, assignments of the methodological block of the USE, measurement of a physical quantity taking into account the absolute error, interpretation of the experiment results.

\section{Введение}

$\Phi$ ГОС второго поколения требует формирования не только системы знаний о методах познания, но и методологических умений. При этом в планируемых результатах обучения главным становится овладение системой методологических умений, а не освоение традиционной системы предметных умений.

На сегодняшний день проведение натурного эксперимента в рамках ЕГЭ по физике невозможно из-за отсутствия технического обеспечения. ФИПИ конструировал модельные тестовые задания для проверки планируемого результата овладения системой методологических умений. В связи с этим умения, которые проверяют посредством модельных заданий КИМ ЕГЭ по физике, называют теоретическими методологическими умениями. Тестовые задания проверяют, владеет ли ученик приемами исследовательской деятельности при эмпирическом методе познания.

Анализ результатов ЕГЭ по физике за 4 последних лет
Петрова Раиса Иннокентьевна

К.т.н., дочент, ФГАОУ ВО «Северо-Восточный федеральный

университет им М.К. Аммосова» (Якутск) rain72@mail.ru

Сидорова Фекла Любомировна ФГАОУ ВО «Северо-Восточный федеральный университет им М.К. Аммосова» (Якутск) fekla230694@mail.ru

Аннотация: ФГОС второго поколения требует формирования у учащихся методологических умений, проверяемых посредством модельных заданий КИМ ЕГЭ по физике. Тестовые задания проверяют, владеет ли ученик приемами исследовательской деятельности при эмпирическом методе познания. Проведена классификация заданий методологического блока ЕГЭ, выявлены шесть типов заданий. Разработаны обобщенные приемы деятельности по выполнению заданий шести типов, основываясь на структуру деятельностей, описанных в планируемых результатах. Применение обобщенных приемов к конкретным заданиям методологического блока ЕГЭ доказало эффективность их использования.

Ключевые слова: методологические умения, обобщенные приемы деятельности, задания методологического блока ЕГЭ, измерение физической величины с учетом абсолютной погрешности, интерпретация результатов опыTOB».

показал, что средний процент выполнения заданий методологического блока колеблется от $43 \%$ до $79 \%$, что требует дальнейших исследований возможностей формирования умения выполнять такие задания.

Задания методологического блока в демонстрационных версиях ФИПИ многочисленны и имеется предположение, что их со временем станет больше, так как этого требует современная жизнь. При обучении учащихся выполнению отдельно каждого задания, возникает вопрос: где взять время для формирования этих частных умений. Не проще ли выделить действия, которые являются общими для частных видов деятельности? Назовем их обобщенными приемами выполнения заданий методологического характера.

Формирование у учащихся обобщенных умений займет немало времени, но в результате они смогут применить их конкретно к любому заданию, количество которых уже не будет иметь значения. Теперь встает вопрос: каково должно быть содержание этих обобщенных приемов? То есть надо искать ответ на вопрос: из каких 
действий должны состоять обобщенные приемы и в какой последовательности эти действия выполнять?

Целью исследования является разработка обобщенных приемов деятельности по выполнению заданий ЕГЭ, проверяющих методологические умения.

В заданиях ЕГЭ имеются 2 задания базового уровня сложности, проверяющие теоретические методологические умения под номерами 22 и 23 [1]. Задания линии 22 оценивают деятельность «измерение величины с учетом абсолютной погрешности, а задания линии 23 - интерпретация результатов опыта». Анализ заданий линии 22 показал, что они проверяют, умеют ли учащиеся снимать показания приборов и записывать значения физических величин с учётом абсолютной погрешности измерений [2]. При этом в тексте задания дают значение абсолютной погрешности в виде половины цены деления или в виде цены деления. Нами установлено, что среди заданий линии 22 есть задания, которые проверяют умение находить погрешность не только прямых, но и косвенных измерений. Анализ заданий линии 23 показал, что задания проверяют умение выбирать экспериментальные установки или приборы, оборудования, материалы для проведения опыта. Предлагаются 3 модели заданий. Первая модель заданий предлагает для опыта выбирать две схематические рисунки установок из пяти, вторая две строки о характеристиках установок из пяти строк, а в третьей модели нужно выбрать названия двух из пяти приборов или оборудований установок для выполнения опыта. На наш взгляд, деятельность «интерпретация результатов опыта» заданий линии 23 является сложной и требует уточнения, какие умения она содержит.

Для того чтобы разработать обобщенные приемы, нужно выделить виды деятельности при выполнении

Таблица 1.

Классификация заданий, оценивающих методологические умения

\begin{tabular}{|c|c|l|}
\hline № задания & Типы & \multicolumn{1}{|c|}{ Методологические умения, которые проверяют КИМ ЕГэ } \\
\hline 22 & 1 & Нахождение цены деления. Запись показания прибора сучетом абсолютной погрешности прибора. \\
\hline 22 & 2 & $\begin{array}{l}\text { Нахождение значения физической величины, запись результатов вычисления с учётом их погреш- } \\
\text { ностей. }\end{array}$ \\
\hline 23 & 3 & $\begin{array}{l}\text { Выбор необходимых приборов, оборудований и материалов для нахождения значения физической } \\
\text { величины. }\end{array}$ \\
\hline 23 & 4 & $\begin{array}{l}\text { Выбор необходимых приборов, материалов и экспериментальной установки для проведения иссле- } \\
\text { дований зависимости между величинами. }\end{array}$ \\
\hline 23 & 5 & $\begin{array}{l}\text { Выбор условий эксперимента для проведения исследований зависимости между физическими } \\
\text { величинами. }\end{array}$ \\
\hline 23 & 6 & $\begin{array}{l}\text { Нахождение среднего значения физической величины и запись результатов вычисления с учётом их } \\
\text { погрешностей. }\end{array}$ \\
\hline
\end{tabular}

Таблица 2.

Обобщенные приемы деятельности и примеры выполнения заданий

\begin{tabular}{|c|c|c|}
\hline Тип задания & Системы действий по выполнению заданий & Примеры выполнения заданий \\
\hline $\begin{array}{l}\text { Тип 1. Нахождение } \\
\text { погрешности прямого } \\
\text { измерения }\end{array}$ & $\begin{array}{l}\text { 1. Внимательно прочитайте задание. Определите, какую вели- } \\
\text { чину следует измерить. } \\
\text { 2. Рассмотрите показания прибора, предназначенного для } \\
\text { измерения искомой величины, и определите цену деления } \\
\text { прибора. } \\
\text { 3. Определите погрешность измерения, руководствуясь } \\
\text { текстом задачи. Округлите показание прибора до указанной } \\
\text { погрешности. } \\
\text { 4. Запишите в поле ответа КИМ показание прибора и погреш- } \\
\text { ность в соответствии с рекомендациями записи по условию } \\
\text { задачи. Перенесите в бланк ответов №1 только числа, не раз- } \\
\text { деляя их пробелом или другим знаком. }\end{array}$ & 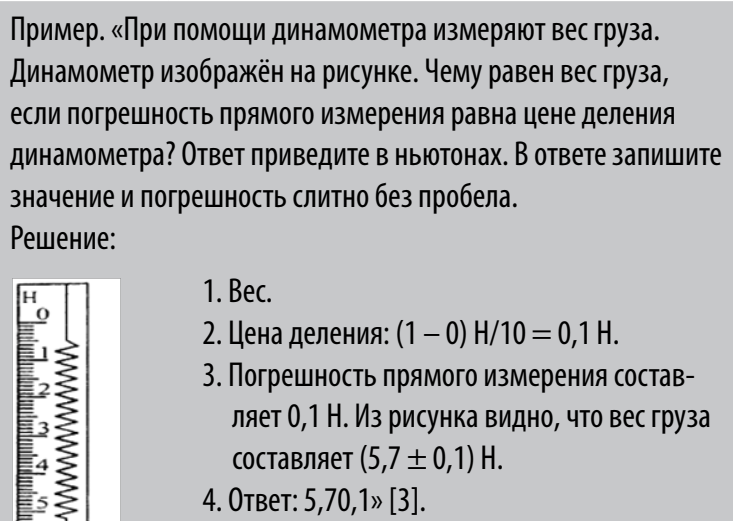 \\
\hline
\end{tabular}




\begin{tabular}{|c|c|c|}
\hline Тип задания & Системы действий по выполнению заданий & Примеры выполнения заданий \\
\hline $\begin{array}{l}\text { Тип 2. Нахождение по- } \\
\text { грешности косвенного } \\
\text { измерения }\end{array}$ & $\begin{array}{l}\text { 1. Внимательно прочитайте задачу. Определите, какую величи- } \\
\text { ну следует найти. } \\
\text { 2. Найдите показания прибора, предназначенного для измере- } \\
\text { ния величины, и вычислите искомую величину. } \\
\text { 3. Определите погрешность искомой величины. } \\
\text { 4. Напишите искомую величину с учетом погрешности. Окру- } \\
\text { глите величину до указанной погрешности. } \\
\text { 5. Запишите в поле ответа КИМ показание прибора и погреш- } \\
\text { ность в соответствии с рекомендациями записи по условию } \\
\text { задания. Перенесите в бланк ответов №1 числа. }\end{array}$ & 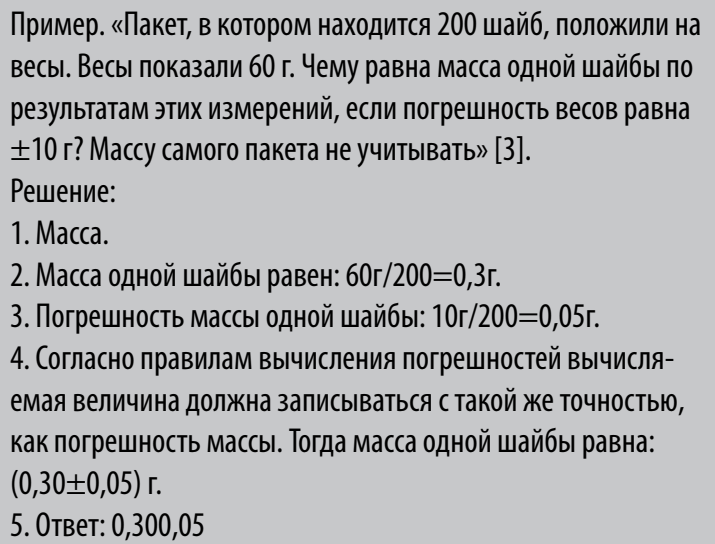 \\
\hline $\begin{array}{l}\text { Тип 3. Выбор приборов } \\
\text { и оборудований для } \\
\text { экспериментального } \\
\text { нахождения значения } \\
\text { физической величины }\end{array}$ & $\begin{array}{l}\text { 1. Внимательно прочитайте задачу, при наличии рисунков, } \\
\text { графиков, таблиц с экспериментальными данными изучите их. } \\
\text { Определите, какую величину следует найти. } \\
\text { 2. Напишите формулу для нахождения искомой физической } \\
\text { величины. } \\
\text { 3. Перечислите величины для нахождения искомой величины. } \\
\text { 4. Определите, какие приборы и оборудования необходимы } \\
\text { для измерения величин. } \\
\text { 5. Выберите верные варианты ответов, основываясь на спосо- } \\
\text { бах нахождения перечисленных величин. Запишите цифры, } \\
\text { которыми обозначены выбранные варианты, в поле ответа } \\
\text { ким и бланке ответов№1. }\end{array}$ & $\begin{array}{l}\text { Пример. «Необходимо собрать экспериментальную установку, } \\
\text { с помощью которой можно определить мощность электри- } \\
\text { ческого тока, потребляемого лампочкой. Для этого помимо } \\
\text { лампочки школьник взял соединительные провода, реостат, } \\
\text { ключ и аккумулятор. Какие два предмета из приведенного } \\
\text { ниже перечня оборудования необходимо дополнительно ис- } \\
\text { пользовать для проведения данного эксперимента? } \\
\text { 1) Реостат } \\
\text { 2) Амперметр } \\
\text { 3) Вольтметр } \\
\text { 4) Конденсатор } \\
\text { 5) Катушка индуктивности. } \\
\text { В ответе запишите номера выбранных предметов» [3]. } \\
\text { Решение: } \\
\text { 1. Мощность электрического тока. } \\
\text { 2. Мощность электрического тока можно найти по формуле } \\
\text { Р=І*U. } \\
\text { 3. Физические приборы, необходимые для измерения силы } \\
\text { тока и напряжения: амперметр и вольтметр. } \\
\text { 4. Ответ: 23 }\end{array}$ \\
\hline $\begin{array}{l}\text { Тип 4. Выбор при- } \\
\text { боров, материалов и } \\
\text { экспериментальной } \\
\text { установки для иссле- } \\
\text { дования зависимости } \\
\text { между физическими } \\
\text { величинами. }\end{array}$ & $\begin{array}{l}\text { 1. Внимательно прочитайте задачу, при наличии рисунков, } \\
\text { графиков, таблиц с экспериментальными данными изучите } \\
\text { их. Определите, какая величина зависит от какой другой } \\
\text { величины? } \\
\text { 2. Напишите формулу зависимости между величинами. } \\
\text { 3. Определите, какую величину надо изменять. } \\
\text { 4. Определите, какие величины остаются постоянными. } \\
\text { 5. Выберите верные варианты ответов, основываясь на } \\
\text { предыдущий анализ. Запишите цифры, которыми обозначены } \\
\text { выбранные варианты, в поле ответа КИМ и бланке ответов№1 }\end{array}$ & $\begin{array}{l}\text { Пример. «Необходимо обнаружить зависимость частоты } \\
\text { свободных электромагнитных колебаний в колебательном } \\
\text { контуре от индуктивности катушки. Какие два колебательных } \\
\text { контура надо выбрать для проведения такого опыта?» [3]. } \\
\text { Решение: } \\
\text { 1. Частота свободных электромагнитных колебаний зависит от } \\
\text { индуктивности катушки». } \\
\text { 2. } \omega=\frac{1}{2 \pi \sqrt{L C}} \\
\text { 3. Индуктивность катушки L. } \\
\text { 4. Емкость C. } \\
\text { 5. Ответ:14 }\end{array}$ \\
\hline
\end{tabular}




\begin{tabular}{|c|c|c|c|c|c|c|c|c|}
\hline Тип задания & Системы действий по выполнению заданий & \multicolumn{7}{|c|}{ Примеры выполнения заданий } \\
\hline $\begin{array}{l}\text { Тип 5. Выбор условий } \\
\text { эксперимента при ис- } \\
\text { следовании зависимо- } \\
\text { сти между физически- } \\
\text { ми величинами. }\end{array}$ & $\begin{array}{l}\text { 1. Внимательно прочитайте задачу, при наличии рисунков, } \\
\text { графиков, таблиц с экспериментальными данными изучите } \\
\text { их. Определите, какая величина зависит от какой другой } \\
\text { величины? } \\
\text { 2. Определите, какую величину надо изменять. } \\
\text { 3. Определите, какие условия опыта остаются постоянными. } \\
\text { 4. Выберите верные варианты ответов, основываясь на } \\
\text { предыдущий анализ. Запишите цифры, которыми обозначены } \\
\text { выбранные варианты, в поле ответа КИМ и бланке ответов № }\end{array}$ & \multicolumn{7}{|c|}{ 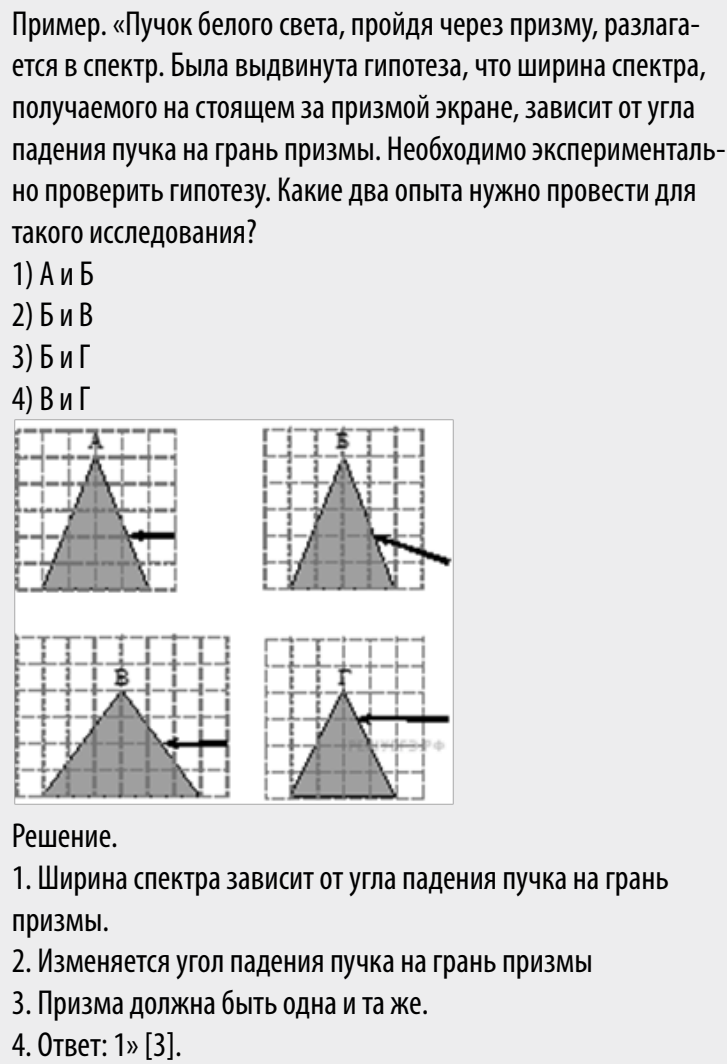 } \\
\hline \multirow[t]{8}{*}{$\begin{array}{l}\text { Тип 6. Вычисление } \\
\text { физической величины } \\
\text { по экспериментально } \\
\text { полученным данным. }\end{array}$} & \multirow{8}{*}{$\begin{array}{l}\text { 1. Внимательно прочитайте задачу, при наличии рисунков, } \\
\text { графиков, таблиц с экспериментальными данными изучите их. } \\
\text { Определите, какую величину следует найти. } \\
\text { 2. Напишите формулу для нахождения искомой физической } \\
\text { величины. } \\
\text { 3. Вычислите искомую величину при каждом измерении. } \\
\text { Добавьте новую строку в таблицу и занесите значения искомой } \\
\text { величины. } \\
\text { 4. Найдите среднее значение искомой величины. } \\
\text { 5. Запишите в поле ответа КИМ величину в соответствии с ре- } \\
\text { комендациями записи по условию задачи. Перенесите в бланк } \\
\text { ответов №1 числа. }\end{array}$} & \multicolumn{7}{|c|}{$\begin{array}{l}\text { Пример. «Исследовалась зависимость напряжения на обклад- } \\
\text { ках конденсатора от заряда этого конденсатора. Результаты } \\
\text { измерений представлены в таблице. Погрешности измерений } \\
\text { величин q и U равнялись соответственно 0,5 мкКл и 0,2 кВ. } \\
\text { Чему примерно равна ёмкость конденсатора? (Ответ дайте в } \\
\text { нФ с точностью до целых.) }\end{array}$} \\
\hline & & $\begin{array}{c}q, \\
\text { мККл }\end{array}$ & & 1 & 2 & 3 & 4 & 5 \\
\hline & & $U, \mathrm{kB}$ & & 0,4 & 0,6 & & 1,4 & 1,8 \\
\hline & & \multicolumn{7}{|c|}{$\begin{array}{l}\text { » [3]. Решение: } \\
\text { 1. Емкость конденсатора. } \\
\text { 2. C=qU } \\
\text { 3. }\end{array}$} \\
\hline & & $\begin{array}{l}q, \\
\text { мкКл }\end{array}$ & 0 & 1 & 2 & 3 & 4 & 5 \\
\hline & & $\mathrm{U}, \mathrm{kB}$ & 0 & 0,4 & 0,6 & 0,8 & 1,4 & 1,8 \\
\hline & & $\mathrm{C}, \mathrm{H} \Phi$ & - & 2,5 & 3,3 & 3,8 & 2,9 & 2,8 \\
\hline & & \multicolumn{7}{|c|}{ 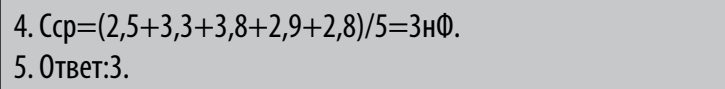 } \\
\hline
\end{tabular}

заданий, оценивающих теоретические методологические умения в процедуре ЕГЭ. Анализ многочисленных заданий (60 заданий) методологического блока привел к классификации заданий. Задания линии № 22 мы разделили на 2 типа, а задания линии № 23 разделили на 4 типа. К каждому типу заданий выявили виды деятельно- сти и умения, которые проверяют методологические задания, результаты классификации приведены в таблице 1.

Нами разработаны обобщенные приемы деятельности по выполнению заданий шести типов, основываясь 
на структуру деятельностей, описанных в планируемых результатах. Обобщенные приемы применены к заданиям демонстрационных версий ФИПИ. В таблице 2 приведены общие системы действий по выполнению заданий соответствующих типов и примеры выполнения заданий каждого типа.

Если известны обобщенные приемы выполнения заданий, встает вопрос, как сделать так, чтобы учащиеся овладели этими приемами на таком уровне, чтобы применить их к любому конкретному методологическому заданию. Известная теория деятельности, которая объясняет природу усвоения человеком любой деятельности, может дать основания для разработки методики освоения этих обобщенных умений. Деятельностный подход в обучении, основанный на данной теории, считает, что знания не могут быть усвоены вне деятельности [4]. Таким образом, нужно разработать методику обучения учащихся разработанным обобщенным приемам, основанную на организацию собственной деятельности самих учащихся.

\section{ЛИТЕРАТУРА}

1. Демидова М.Ю. Методические рекомендации для учителей, подготовленные на основе анализа типичных ошибок участников ЕГЭ 2019 года по физике // Федеральный институт педагогических измерений. [Электронный ресурс]. URL: http://doc.fipi.ru/ege/analiticheskie-i-metodicheskie-materialy/2019/ fizika_2019.pdf (дата обращения: 27.02.2021).

2. Петрова, Р.И. К вопросу о методологических умениях учащихся по физике / Р.И. Петрова, Ф.Л. Сидорова // Современные проблемы науки и образования. 2020. №4. С. 25. [Электронный ресурc]. URL: https://science-education.ru/article/view?id=29968 (дата обращения 27.02.2021).

3. ЕГЭ 2021, физика: задания, ответы, решения. Обучающая система Дмитрия Гущина. [Электронный ресурс]. URL: https://phys-ege.sdamgia.ru (дата 06ращения 25.02.2021.

4. Анофрикова С.В. Азбука учительской деятельности, иллюстрированная примерами деятельности учителя физики Ч.1. Разработка уроков. [Изд. 2-е, перераб. и доп.]. М.: МПГУ. 2007. 325 с.

\section{( Петрова Раиса Иннокентьевна (rain72@mail.ru), Сидорова Фекла Любомировна (fekla230694@mail.ru).}

Журнал «Современная наука: актуальные проблемы теории и практики»

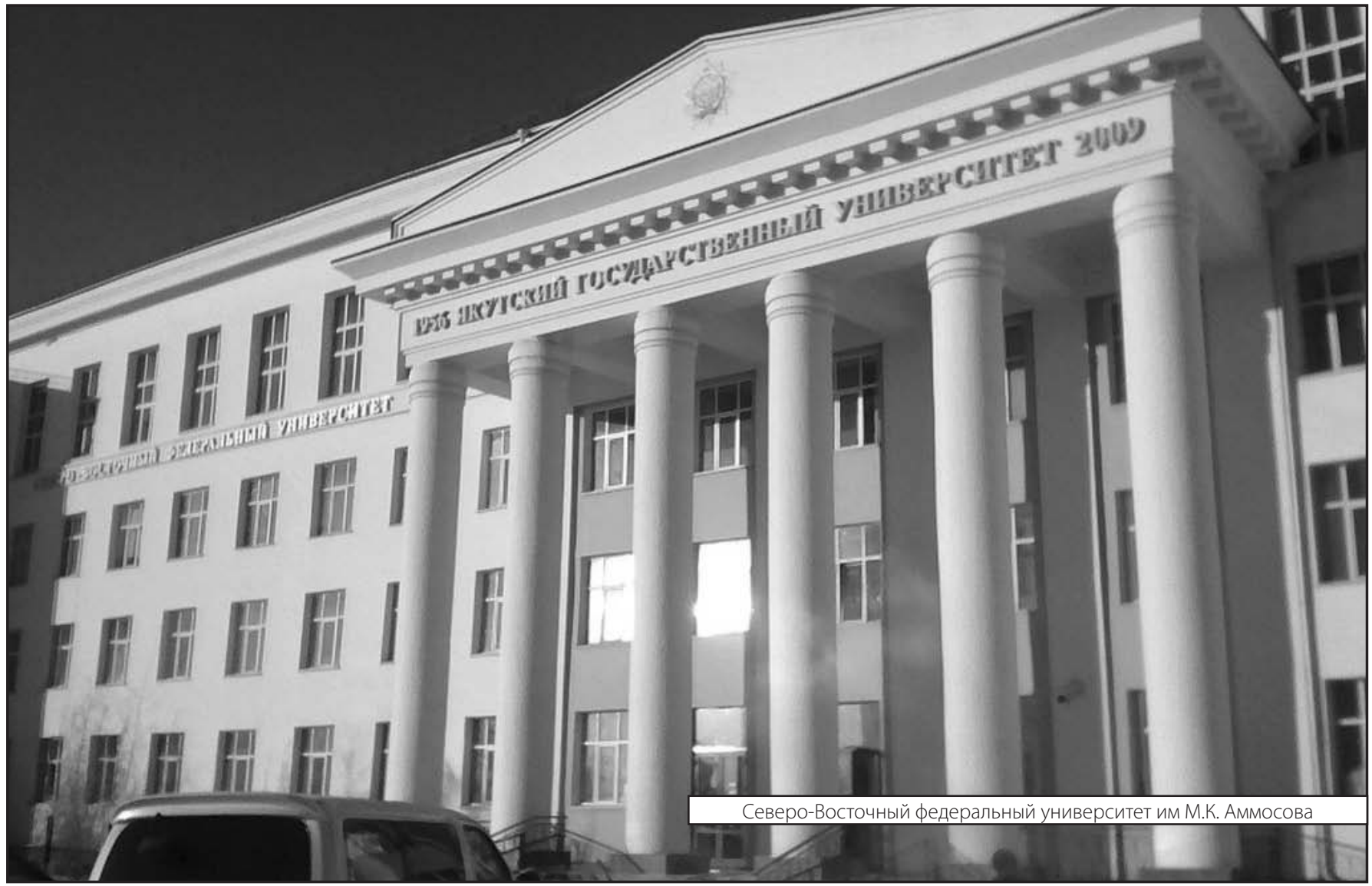

